\title{
p63 and Brg1 control developmentally regulated higher-order chromatin remodelling at the epidermal differentiation complex locus in epidermal progenitor cells
}

\section{Andrei N. Mardaryev1 ${ }^{1}$, Michal R. Gdula ${ }^{1,2}$, Joanne L. Yarker ${ }^{1}$, Vladimir U. Emelianov ${ }^{3}$, Krzysztof Poterlowicz $^{1}$, Andrey A. Sharov ${ }^{3}$, Tatyana Y. Sharova ${ }^{3}$, Julie A. Scarpa ${ }^{1}$, Boris Joffe ${ }^{4}$, Irina Solovei ${ }^{4}$, Pierre Chambon ${ }^{5}$, Vladimir A. Botchkarev ${ }^{1,3}$ and Michael Y. Fessing ${ }^{1}$ \\ ${ }^{1}$ Centre for Skin Sciences, University of Bradford, Bradford BD7 1DP, UK. ${ }^{2}$ The Welcome Trust Centre for Human Genetics, Oxford University, Oxford OX3 7BN, UK. ${ }^{3}$ Department of Dermatology, Boston University School of Medicine, Boston, MA 02118, USA. ${ }^{4}$ Human Biology and Bioimaging, Ludwig-Maximillians University Munich, D-82152 Martinsried, Germany. Institut Génétique Biologie Moléculaire Cellulaire, Illkirch, INSERM U964, CNRS UMR7104, Université de Strasbourg, 67404 Illkirch, France.}

There were errors published in Development 141, 101-111.

Boris Joffe and Irina Solovei have been added to the author list for their contribution to the design of 3D-FISH experiments and data analysis. The middle initial of Vladimir U. Emelianov has been corrected. These changes have been incorporated into the revised author list and affiliations, as shown above, and are accounted in the revised Acknowledgements and Author contributions sections, as shown below.

\section{Acknowledgements}

We greatly appreciate the invaluable help and support of Prof. T. Cremer (Ludwig-Maximillians University Munich, Germany) in establishing 3D-FISH technology and data analysis.

\section{Author contributions}

A.N.M. designed and undertook experiments, analysed results and helped write the paper; M.R.G. and J.L.Y. undertook experiments, analysed results and helped to write the paper; V.U.E., A.A.S., T.Y.S. and J.A.S. undertook experiments and analysed results; K.P. analysed results and helped to write the paper; B.J. and I.S. designed experiments and performed data analysis; P.C. provided crucial reagents and helped to write the paper; V.A.B. and M.Y.F. designed the experiments, analysed results and wrote the paper.

In addition, In Fig. 3A the white and grey bars were incorrectly labelled in the key. The corrected Fig. 3A appears below.

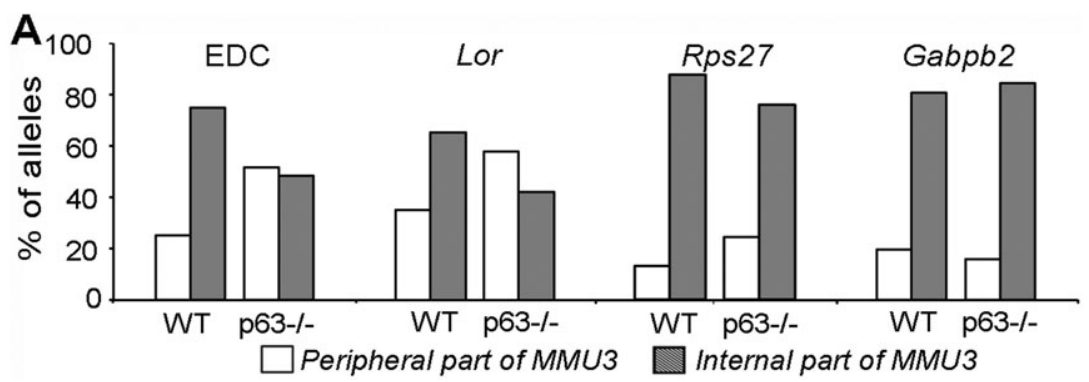

The authors apologise to readers for these mistakes. 


\title{
p63 and Brg1 control developmentally regulated higher-order chromatin remodelling at the epidermal differentiation complex locus in epidermal progenitor cells
}

\author{
Andrei N. Mardaryev ${ }^{1}$, Michal R. Gdula ${ }^{1,2, *}$, Joanne L. Yarker ${ }^{1, *}$, Vladimir N. Emelianov ${ }^{3}$, \\ Krzysztof Poterlowicz ${ }^{1}$, Andrey A. Sharov ${ }^{3}$, Tatyana Y. Sharova ${ }^{3}$, Julie A. Scarpa ${ }^{1}$, Pierre Chambon ${ }^{4}$, \\ Vladimir A. Botchkarev ${ }^{1,3, \ddagger}$ and Michael Y. Fessing ${ }^{1, \ddagger}$
}

\begin{abstract}
Chromatin structural states and their remodelling, including higherorder chromatin folding and three-dimensional (3D) genome organisation, play an important role in the control of gene expression. The role of $3 \mathrm{D}$ genome organisation in the control and execution of lineage-specific transcription programmes during the development and differentiation of multipotent stem cells into specialised cell types remains poorly understood. Here, we show that substantial remodelling of the higher-order chromatin structure of the epidermal differentiation complex (EDC), a keratinocyte lineage-specific gene locus on mouse chromosome 3 , occurs during epidermal morphogenesis. During epidermal development, the locus relocates away from the nuclear periphery towards the nuclear interior into a compartment enriched in SC35-positive nuclear speckles. Relocation of the EDC locus occurs prior to the full activation of EDC genes involved in controlling terminal keratinocyte differentiation and is a lineage-specific, developmentally regulated event controlled by transcription factor $\mathrm{p} 63$, a master regulator of epidermal development. We also show that, in epidermal progenitor cells, p63 directly regulates the expression of the ATP-dependent chromatin remodeller Brg1, which binds to distinct domains within the EDC and is required for relocation of the EDC towards the nuclear interior. Furthermore, Brg1 also regulates gene expression within the EDC locus during epidermal morphogenesis. Thus, p63 and its direct target Brg1 play an essential role in remodelling the higher-order chromatin structure of the EDC and in the specific positioning of this locus within the landscape of the 3D nuclear space, as required for the efficient expression of EDC genes in epidermal progenitor cells during skin development.
\end{abstract}

KEY WORDS: Brg1, Smarca4, Chromatin, Epidermis, Epigenetics, Keratinocyte, p63, Trp63, Mouse

\section{INTRODUCTION}

Tissue development and homeostasis are governed via the establishment of lineage-specific programmes of gene expression in defined populations of multipotent progenitor cells and their

${ }^{1}$ Centre for Skin Sciences, University of Bradford, Bradford BD7 1DP, UK. ${ }^{2}$ The Welcome Trust Centre for Human Genetics, Oxford University, Oxford OX3 7BN, UK. ${ }^{3}$ Department of Dermatology, Boston University School of Medicine, Boston, MA 02118, USA. ${ }^{4}$ Institut Génétique Biologie Moléculaire Cellulaire, Illkirch, INSERM U964, CNRS UMR7104, Université de Strasbourg, 67404 IIIkirch, France.

*These authors contributed equally to this work

${ }^{\ddagger}$ Authors for correspondence (v.a.botchkarev@bradford.ac.uk; m.fessing@bradford.ac.uk)

Received 29 August 2013; Accepted 26 September 2013 differentiating progeny. Lineage-specific programmes of gene expression are characterised by distinct patterns of gene activation and silencing and are regulated at several levels, including the epigenetic control of chromatin structural states (Rando and Chang, 2009; Wang et al., 2009). Epigenetic regulatory mechanisms control covalent DNA and histone modifications, ATP-dependent chromatin remodelling, higher-order chromatin folding and the specific arrangement of genes and distinct chromatin domains within threedimensional (3D) nuclear space (Hubner et al., 2012; Naumova and Dekker, 2010; Rando and Chang, 2009; Wang et al., 2009).

Within the interphase nucleus, genes and genomic loci are nonrandomly distributed relative to the nuclear periphery, the nuclear interior and nuclear landmarks, including chromosomal territories (CTs) and other genes or distinct nuclear bodies (Bickmore and van Steensel, 2013; Cremer and Cremer, 2010; Hubner et al., 2012). A number of studies have found that inactive genes and gene loci are often situated close to the nuclear membrane, whereas active genes have been observed largely to occupy a more internal nuclear position (Kosak et al., 2002; Takizawa et al., 2008; Williams et al., 2006). However, for many genes transcriptional activity does not always correlate with radial distribution. Rather, the positioning of these genes is determined by the gene density of the corresponding genomic loci or by other factors, such as the proximity to distinct nuclear bodies, that facilitate or inhibit transcription (Brown et al., 2008; Goetze et al., 2007; Küpper et al., 2007; Mao et al., 2011; Yang et al., 2011).

The development and application of chromatin conformation capture (3C, 4C, 5C and Hi-C) technologies to the study of nuclear architecture have shown that actively transcribed genes in the nucleus tend to associate closely with one another and form active domains within CTs, whereas inactive genes form silenced chromosomal domains (Lieberman-Aiden et al., 2009). Furthermore, data obtained using super-resolution confocal microscopy have revealed a network of channels and lacunas within both euchromatin and heterochromatin, implicating a large degree of flexibility in the positioning of genes and chromosomal domains relative to each other in the interphase nucleus (Markaki et al., 2010). Threedimensional fluorescent in situ hybridisation (3D-FISH) data show that some genes and gene loci 'loop out' from the major body of the $\mathrm{CT}$ after activation or when in a highly active state (Chambeyron and Bickmore, 2004; Chambeyron et al., 2005; Ferrai et al., 2010; Williams et al., 2004). However, many actively transcribed genes are also found on the surface of CTs or within them (Boyle et al., 2011; Küpper et al., 2007), supporting the view that gene positioning and transcriptional activity are determined by many, as yet unknown, factors and conditions that vary in different cell types (Bickmore and van Steensel, 2013). 
Skin epithelium (the epidermis) is a self-renewing tissue that contains discrete populations of multipotent progenitor cells (Blanpain and Fuchs, 2009). Differentiation of epithelial progenitor cells, which reside in the basal epidermal layer, into keratinocytes of the suprabasal layer is accompanied by a significant increase in the expression of multiple genes residing within the epidermal differentiation complex (EDC) locus. Located in the gene-rich region of mouse chromosome 3, the EDC encodes components of the cornified cell envelope essential for epidermal barrier formation (de Guzman Strong et al., 2010; Fessing et al., 2011; Martin et al., 2004; Segre, 2006) (Fig. 1A). The programme of epidermal morphogenesis in mice begins at approximately embryonic day (E) 9.5 and is followed by the onset of epidermal stratification at E14.5, resulting in the formation of a functional epidermal barrier at E18.5 (Blanpain and Fuchs, 2009; Gierman et al., 2007).

The programme of epidermal differentiation is maintained throughout the lifespan of an organism and is regulated at several levels by numerous signalling pathways and transcription factors, as well as epigenetically (reviewed by Blanpain and Fuchs, 2009; Botchkarev et al., 2012; Eckert et al., 2011; Frye and Benitah, 2012; Koster et al., 2007b; Truong and Khavari, 2007; Zhang et al., 2012). In particular, the involvement of the DNA methyltransferase DNMT1, histone demethylase JMJD3 (also known as Kdm6b), histone methyltransferase Setd8, histone deacetylases 1/2, ATPdependent chromatin modifying enzymes Brg1 (also known as Smarca4) and Mi-2 $\beta$ (also known as Chd4), polycomb group proteins Bmi1, Cbx4, Ezh2 and Jarid2, and the genome organiser Satb1 in establishing tissue-specific differentiation programmes in the epidermis has been demonstrated (Aarenstrup et al., 2008; Driskell et al., 2012; Eckert et al., 2011; Ezhkova et al., 2011; Ezhkova et al., 2009; Fessing et al., 2011; Indra et al., 2005; Kashiwagi et al., 2007; Lien et al., 2011; Luis et al., 2011; Mejetta et al., 2011; Sen et al., 2010).

Several indications suggest that epigenetic mechanisms controlling epidermal development and differentiation are guided by transcription factors. Transcription factor p63 (also known as Trp63), a master regulator of epidermal development, directly regulates expression of the genome organiser and AT-rich binding protein Satb1, which is essential for proper higher-order chromatin folding and transcriptional regulation of the EDC locus in keratinocytes (Fessing et al., 2011). Deficiency in p63 leads to significant changes in the expression of many other genes involved in chromatin organisation and remodelling, including Brg1 (Fessing et al., 2011). Brgl ablation is associated with alterations in epidermal barrier formation in embryonic skin, as well as with defects in hair follicle stem cell activity and hair loss in adult mice (Indra et al., 2005; Xiong et al., 2013). However, many aspects of the $3 \mathrm{D}$ genome organisation in epidermal progenitor cells, including the regulatory mechanisms that control higher-order chromatin remodelling during distinct stages of epidermal development, remain to be elucidated.

Here, we demonstrate that, during epidermal development, increased transcriptional activity within the EDC locus is associated with marked reorganisation of the higher-order chromatin architecture of the locus and its relocation from the nuclear periphery towards the nuclear interior into a compartment enriched in SC35 (Srsf2)-positive nuclear speckles. Furthermore, we show that profound changes in the gene expression profile of the EDC, caused by loss of p63, are associated with changes in the developmentally regulated relocation of the EDC within the nucleus. Finally, we show that the ATP-dependent chromatin remodeller Brg1 is a direct p63 target and that Brg1 contributes to the developmentally regulated relocation of the EDC towards the nuclear interior in epidermal progenitor cells.

\section{RESULTS}

\section{A developmentally regulated increase in transcriptional activity within the EDC locus is accompanied by its relocation towards the nuclear interior in epidermal progenitor cells}

The EDC locus occupies $\sim 3.1 \mathrm{Mb}$ in the gene-rich region of mouse chromosome 3 . Its central domain contains a large number of genes involved in epidermal stratification and barrier acquisition, including loricrin (Lor), the Sprr gene family, Ivl, the Lce gene family and Flg (de Guzman Strong et al., 2010) (Fig. 1A). Several genes that are also expressed in tissues other than the epidermis flank the EDC, including members of the S100 gene family and the Rps 27 and Gabpb2 genes, which encode ribosomal protein $\mathrm{S} 27$ and GA repeat binding protein beta 2 , respectively (Fig. 1A).

To define the dynamics of gene expression within the EDC and neighbouring regions of mouse chromosome 3 in epidermal keratinocytes and dermal cells (used as a control), we utilised lasercapture micro-dissection (LCM) followed by microarray and quantitative (q) RT-PCR analyses. In epidermal keratinocytes at E11.5 (prior to epidermal stratification), the expression of keratinocyte-specific genes that comprise the central EDC domain, such as Lor and genes of the Lce family, was low or moderate. Between E14.5 and E16.5, however, the transcriptional activity of these genes was seen to steadily increase, reaching the maximum level of expression in the adult epidermis (Fig. 1B; supplementary material Table S1). Genes of the S100 family, which occupy the 5' and 3' EDC flanking regions, however, showed only moderate changes in expression between E11.5, E16.5 and adult epidermis (Fig. 1B; supplementary material Table S1). In contrast to keratinocytes, developmentally regulated changes in the transcriptional activity of genes within the central EDC domain did not occur in dermal cells, in which only low-level expression of these genes was observed (Fig. 1B; supplementary material Table S1).

During development of the epidermis, distinct differences in the expression pattern of two genes neighbouring the EDC, Rps 27 and Gabpb2 (supplementary material Fig. S1A), were observed. Located within the $5^{\prime}$ flanking region of the EDC at a distance of $0.3 \mathrm{Mb}$ from the locus, the expression level of the Rps 27 housekeeping gene remained very high during all stages of development (supplementary material Table S2). However, the transcriptional activity of Gabpb2, which is located in the $3^{\prime}$ flanking region of the EDC at a distance of $1.5 \mathrm{Mb}$ from the locus, was low during all stages of epidermal development (supplementary material Table S2).

We examined whether developmentally regulated increases in the activity of the EDC locus and the Lor gene located within the locus are associated with any changes in their position within the nucleus and their position in relation to chromosomal territory 3 (CT3 or MMU3). To address this question, 3D-FISH experiments were performed on mouse skin at distinct time points of embryonic and postnatal development [E11.5, E16.5, postnatal day (P) 10.5, 6 months old] using distinct DNA probes generated from BAC clones covering either the entire EDC or specifically the Lor locus together with MMU3 paint (Fig. 1A; supplementary material Table S3). The positioning of the EDC and of Lor in keratinocyte nuclei was compared with that of neighbouring control genes Rps 27 and Gabpb2 relative to distinct parts (peripheral and internal) of MMU3, which in keratinocytes is located within the outer nuclear region in the vicinity of the nuclear membrane (Fig. 1C,E). The peripheral part of the CT 
A

\begin{tabular}{|c|c|c|c|c|c|c|c|c|c|}
\hline \multicolumn{10}{|c|}{ EDC } \\
\hline & Rps2 & S100 genes & Lor & Sprr genes & Ivl & Lce genes & $\mathrm{Flg}$ & S100 genes & Gabpb2 \\
\hline $\begin{array}{c}\text { 3D-FISH } \\
\text { probes }\end{array}$ & 90 & $\stackrel{90.3-90.5}{\square}$ & $\begin{array}{r}91.9 \\
\square\end{array}$ & $\begin{array}{l}92-92.3 \\
\text { Length of }\end{array}$ & $\begin{array}{r}92.4 \\
f \text { 吕 }\end{array}$ & $\begin{array}{l}92.4-92.8 \\
\text { (Mbp) }\end{array}$ & 93.1 & $\begin{array}{c}93.3-93.4 \\
\square\end{array}$ & $\begin{array}{l}95 \\
\square\end{array}$ \\
\hline
\end{tabular}

B

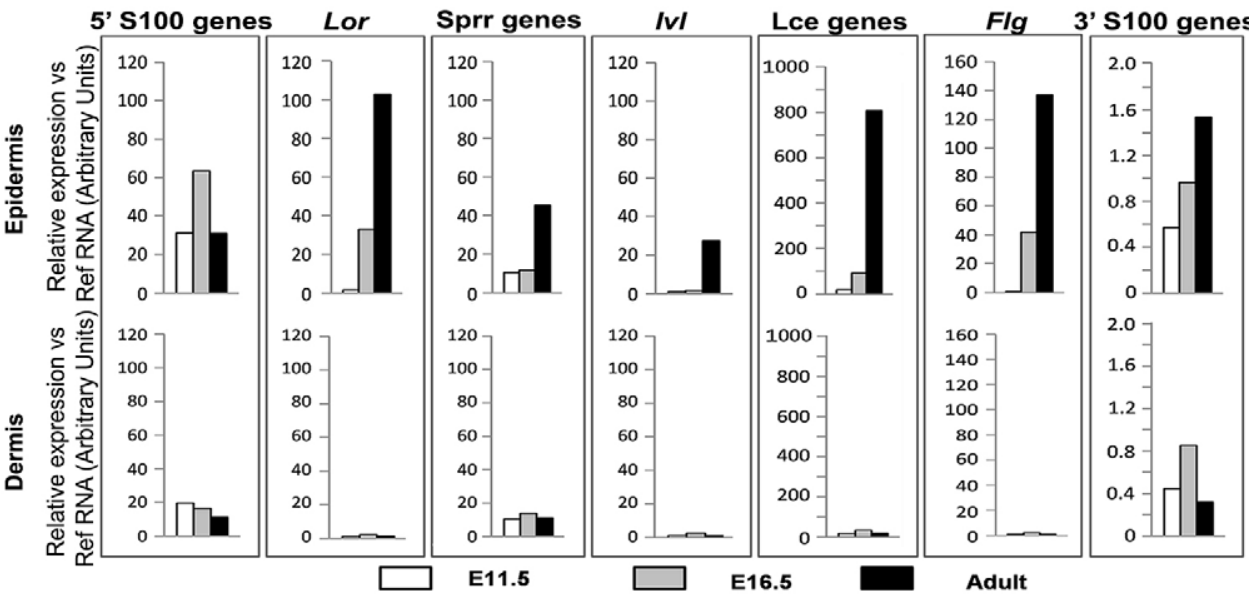

C

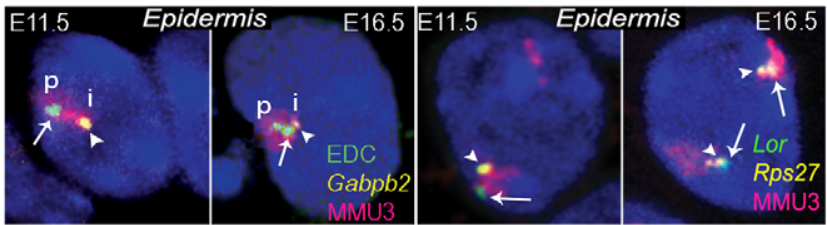

E
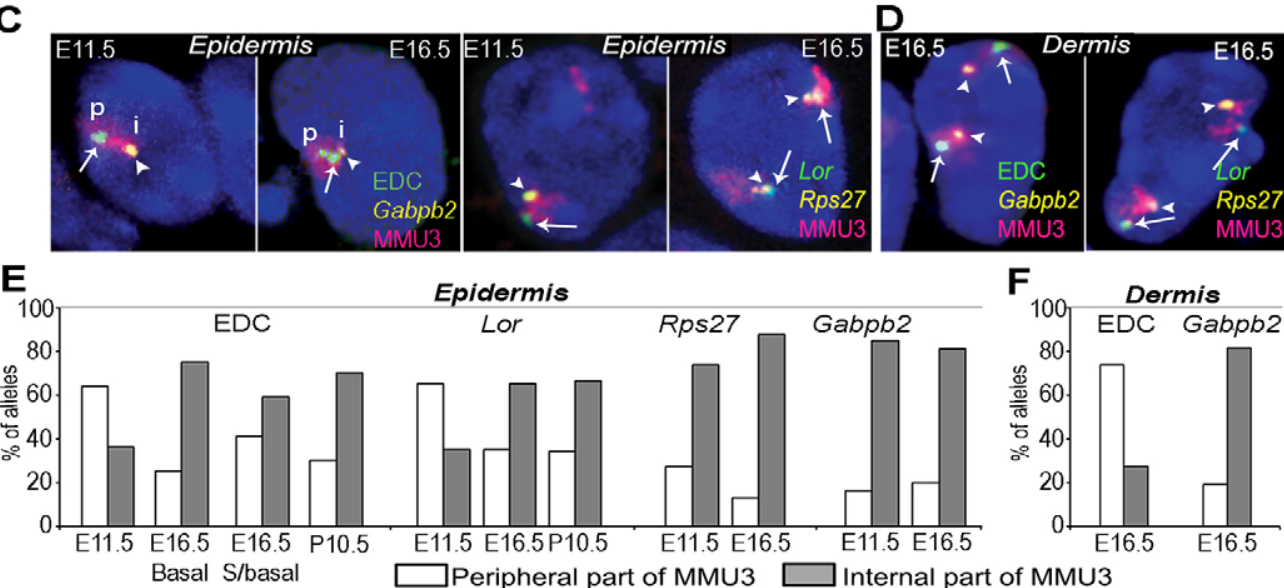

$\mathbf{F}$
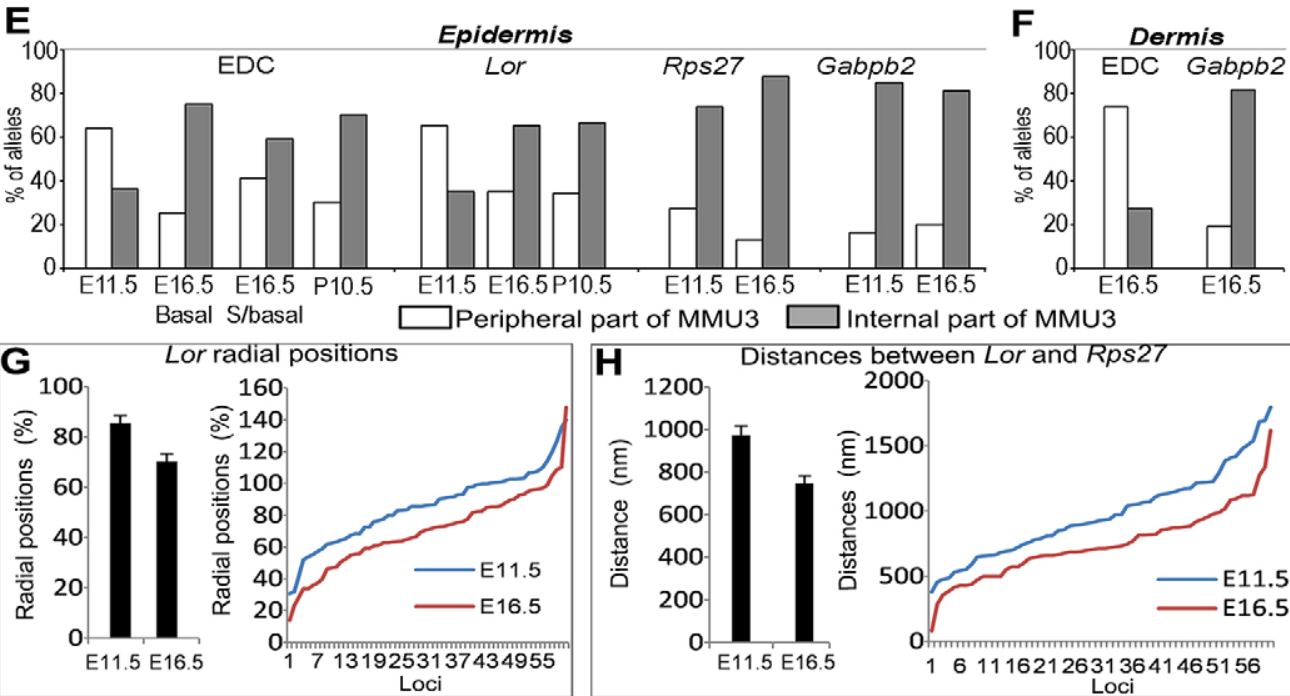

Fig. 1. Dynamics of transcriptional activity within the EDC locus and its relocation within the 3D nuclear space in developing skin. (A) Schematic structure of the $5 \mathrm{Mb}$ domain on mouse chromosome 3 containing the EDC locus, Rps27 and Gabpb2. 3D-FISH DNA probes detecting the corresponding domains are shown in green (EDC) and yellow (Rps27, Gabpb2). Tel, telomere. (B) Microarray analysis of RNA from laser-captured epidermis and dermis of mice at distinct stages of development. Means are shown for relative transcriptional activity normalised to the reference RNA levels for the indicated genes and gene families in the EDC. Three samples were used for each stage. (C,D) Multicolour 3D-FISH with BACs containing the EDC, Lor, Rps27, Gabpb2 or mouse chromosome territory 3 (MMU3) in epidermal (C) and dermal (D) cells at E11.5 and E16.5. Localisation of the EDC and Lor (arrows) and localisation of Rps27 and Gabpb2 (arrowheads) in distinct parts of MMU3 [peripheral (P) versus internal (i)] are shown in representative single z-sections. Scale bar: $2 \mu \mathrm{m}$. $(E, F)$ Frequencies of the intra-MMU3 distribution of EDC, Lor, Rps27 and Gabpb2 (peripheral versus the internal parts of the MMU3) in basal and suprabasal keratinocytes $(E)$ and dermal cells $(F)$. The percentage of alleles of the EDC and Lor occupying the internal portion of the MMU3 increased at E16.5 in comparison with that at E11.5, whereas the positioning of Rps27 and Gabpb2 in the epidermis or of EDC/Gabpb2 in dermal cells remained mostly unchanged. $n=100 ; P$-values calculated for pairwise comparisons (Chi-square test) are as follows. Epidermis: EDC E11.5 versus E16.5 basal, $P=2.73 \times 10^{-8}$; EDC E11.5 versus E16.5 suprabasal, $P=1.83 \times 10^{-3}$; EDC E16.5 basal versus E16.5 suprabasal, $P=0.024$; EDC E16.5 versus $P 10.5$, $P=0.51 ;$ Lor E11.5 versus E16.5, $P=4.11 \times 10^{-5}$; Lor E16.5 versus P10.5, $P=1.0$; Rps27 E11.5 versus E16.5, $P=0.021$; Gabpb2 E11.5 versus E16.5, $P=0.64$. Dermis: EDC versus Gabpb2, $P=5.5 \times 10^{-14}$. (G) Relative radial position of Lor in basal epidermal keratinocytes normalised to the average radius of the nuclei at $E 11.5$ and $E 16.5$. Mean + s.e.m. and data distribution; $n=60$. In pairwise comparisons, differences between E11.5 versus E16.5 are significant $(P<0.01$, Newman-Keuls test after one-way ANOVA test). (H) Distances between Lor and Rps27 in basal epidermal keratinocytes at E11.5 and E16.5. Mean + s.e.m.; $n=60$. In pairwise comparisons, differences between E11.5 versus E16.5 are significant $(P<0.01$, Newman-Keuls test after one-way ANOVA test). 
was defined as that located furthest from the nuclear centre relative to the $\mathrm{CT}$ centre; the internal part of the $\mathrm{CT}$ was defined by its proximity to the nuclear centre relative to the CT centre.

At E11.5, prior to epidermal stratification, Lor and the entire EDC were located close to the nuclear membrane, mostly occupying the peripheral part of MMU3 (Fig. 1C,E). In contrast to the EDC, both neighbouring genes (the highly transcribed Rps 27 and lesser transcribed Gabpb2) were predominantly located in the inner part of MMU3 at E11.5. At later developmental stages, the position of $G a b p b 2$ within the territory remained unchanged, whereas Rps 27 was observed to have moved slightly towards the internal part of the territory (Fig. 1C,E). At E16.5, after the onset of epidermal stratification, Lor and the EDC were found to predominantly occupy a position within the internal region of MMU3, comparable to that of Rps 27 and Gabpb2, in contrast to their position within the peripheral part of MMU3 at E11.5 (Fig. 1C,E).

In comparison to E16.5 basal epidermal cells, the EDC in suprabasal keratinocytes showed only a slight shift towards the external part of the MMU3 (Fig. 1E). In postnatal epidermis, positioning of the EDC and of Lor in the internal part of the MMU3 was maintained (P10.5, 6-month-old mice) (Fig. 1E; data not shown). Importantly, in dermal cells, Lor and the EDC retained their peripheral position within MMU3 at all stages of embryonic and postnatal development, suggesting that their relocation towards the nuclear interior is indeed keratinocyte specific (Fig. 1D,E; data not shown).

Changes in the nuclear localisation of Lor seen in epidermal progenitor cells between E11.5 and E16.5 were consistent with changes in its radial position relative to the nuclear centre (normalised to the average nuclear radius) and with a significant decrease in the distance between Lor and Rps27 (Fig. 1G,H; supplementary material Fig. S1B). Furthermore, the distance of the EDC from the nuclear membrane significantly increased at E16.5 compared with E11.5, whereas the nuclear position of MMU3 remained largely unchanged (supplementary material Fig. S1C).

\section{The EDC locus becomes increasingly associated with SC35- positive nuclear speckles during epidermal development and stratification}

SC35-positive nuclear speckles are nuclear repositories for RNA processing factors that facilitate efficient gene expression (Brown et al., 2008; Mao et al., 2011). In different cell lineages, many, although not all, highly expressed genes are associated with SC35positive nuclear speckles (Brown et al., 2008; Spector and Lamond, 2011) and/or Pol II transcription factories (Morey et al., 2009:
Schoenefelder et al., 2010). Because epidermal keratinocyte nuclei have a high density of transcription factories within the nucleus at all development stages analysed (data not shown), we examined the distribution of SC35-positive nuclear speckles within the vicinity of the EDC by combining 3D-FISH with immunofluorescence staining using anti-SC35 antibodies (supplementary material Table S8).

The number of SC35-positive speckles in epidermal progenitor cells did not change significantly during transition of the epidermis from a single layer (E11.5) to the multilayered stage (E16.5) (Fig. 2A). However, a significantly higher number of speckles were found within the vicinity of the EDC locus and of Lor in basal and suprabasal epidermal keratinocytes at E16.5 than at E11.5 (Fig. 2B; data not shown). These data demonstrate that the relocation of the EDC and Lor towards the nuclear interior and a developmentally regulated increase in transcriptional activity are associated with an increase in the number of nuclear speckles present within the vicinity of the EDC, suggesting that the speckles play a role in facilitating high levels of gene expression in the EDC locus during epidermal development and stratification.

\section{Developmentally regulated nuclear internalisation of the EDC locus is markedly altered in the skin epithelium of ${\text { p } 63^{-1-} \text { mice }}^{-1}$}

The group of transcription factors encoded by the $p 63$ gene serve as master regulators of epidermal development. $p 63^{-/-}$mice fail to form a stratified epithelium and fail to express a number of epidermis-specific genes (Fessing et al., 2011; Koster et al., 2007a; Koster et al., 2004; Mills et al., 1999; Nguyen et al., 2006; Yang et al., 1999). Lor and the EDC in epithelial cell nuclei in the skin of $p 63^{-/-}$mice, as characterised by the expression of keratin 18 (Koster et al., 2004), occupied a significantly $(P<0.01)$ more peripheral position within MMU3 at E16.5 compared with wild-type (WT) mice (Fig. 3A). Consistent with these observations, the radial position of Lor (normalised for the average nuclear radius) was significantly $(P<0.05)$ increased in nuclei in the skin epithelium of $p 63^{-/-}$mice compared with WT mice (Fig. 3B,C). However, in comparison with WT mice, the position of Rps 27 in $p 63^{-1-}$ mice changed only slightly relative to MMU3 and the position of Gabpb2 remained unchanged (Fig. 3A). Furthermore, the number of SC35positive nuclear speckles within the vicinity of the EDC was significantly $(P<0.05)$ reduced in the epidermis of $p 63^{-/-}$mice in comparison with WT mice (Fig. 3D). These data were consistent with our previous results showing alterations in the $3 \mathrm{D}$ conformation of the EDC locus in $p 63^{-/-}$mice (Fessing et al., 2011). They suggest that p63 also contributes to the developmentally regulated relocation
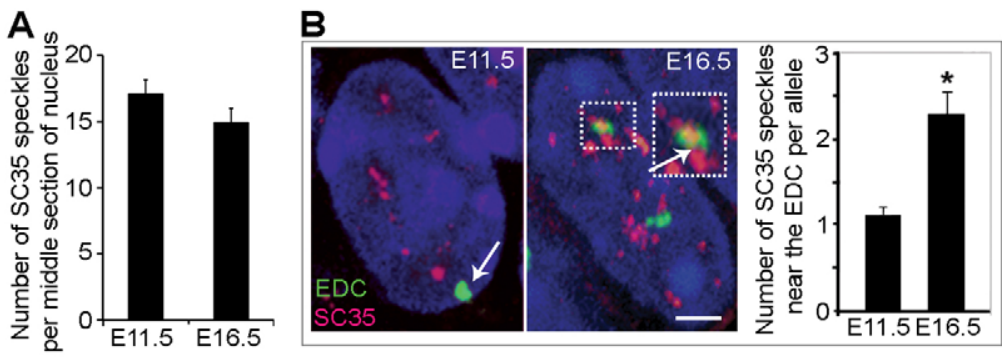

Fig. 2. Developmentally associated changes in the nuclear environment around the EDC locus. (A) Number of SC35-positive nuclear speckles in the middle section of the basal keratinocyte nucleus at E11.5 and E16.5. Mean + s.e.m.; $n=30$. The difference is insignificant $(P=0.18$, two-tailed $t$-test).

(B) Multicolour 3D-FISH with BACs containing the EDC combined with immunostaining for SC35-positive speckles. In representative single optical z-sections, localisation of the EDC in the nuclear interior in physical proximity with an increased number of speckles is indicated by arrows. Scale bar: $2 \mu$ m. The boxed

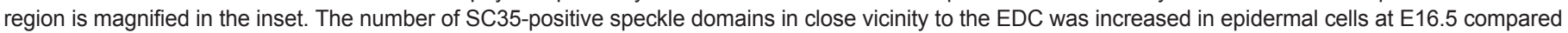
with E11.5. $n=80$; mean + s.e.m.; * $P<0.01$ (Dunn's test after Kruskal-Wallis test). 


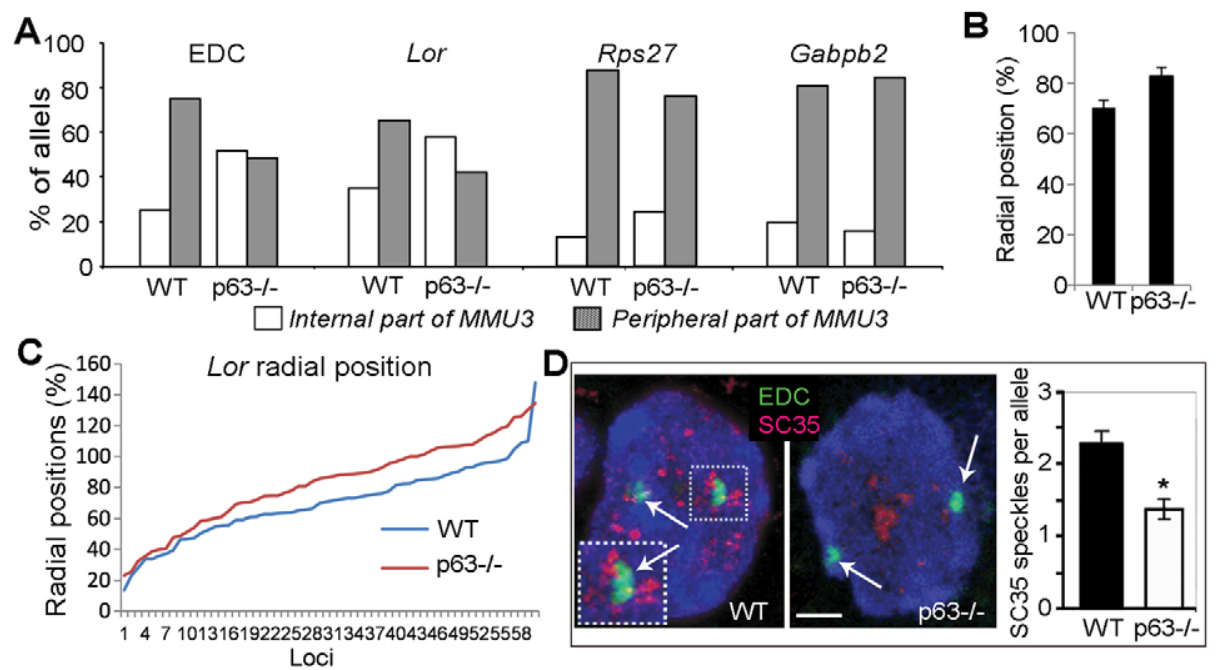

Fig. 3. Alterations in EDC localisation in the epidermis of p63 knockout mice. (A) Results of image analysis after multicolour 3D-FISH with BACs containing the EDC, Lor, Rps27, Gabpb2 and MMU3. Frequencies of intra-MMU3 distribution (peripheral versus the internal parts of the MMU3) of EDC, Lor, $R p s 27$ and Gabpb2 in basal epidermal cells of $p 63^{-/-}$compared with control mice at E16.5. For each sample, $n=100$. $P$-values calculated for pairwise comparison (Chi-square test) are: EDC, $P=2.07 \times 10^{-4}$; Lor, $P=1.81 \times 10^{-3}$; Rps27, $P=0.057$; Gabpb2, $P=0.64$. (B,C) Relative radial position of Lor normalised to the average radius of the nuclei in basal epidermal keratinocytes of WT and $p 63^{-1-}$ mice at $E 16.5$. (B,C) Mean $+s . e . m$. (B) and data distribution $(C)$; $n=60$;

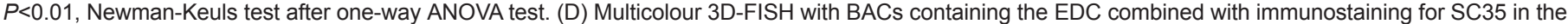
epidermis of WT and $p 63^{-1-}$ mice. Positions of the EDC in epidermal cell nuclei are shown by arrows in representative single $z$-sections. Scale bar: $2 \mu$ m. The number of speckles in proximity to the EDC in $p 63^{-1-}$ mice was decreased compared with WT mice. Mean $+\mathrm{s} . e . \mathrm{m}$.; $n=80 ;{ }^{*} P<0.01$, Dunn's test/Kruskal-Wallis test.

of the EDC and Lor towards the nuclear interior and to their association with nuclear speckles within epidermal progenitor cell nuclei.

\section{Brg1 is a direct p63 target and controls gene expression and nuclear positioning of the EDC in epidermal progenitor cells}

Microarray analysis of the embryonic epidermis of $p 63^{-/-}$mice revealed the downregulation of a number of genes involved in the control of chromatin structural organisation and remodelling, including Brg1, relative to WT mice (Fessing et al., 2011). Bgr1 is normally expressed in epidermal progenitor cells from E10.5 onward, and deficiency in Brg1 leads to defects in epidermal development and barrier formation (Indra et al., 2005). Furthermore, Brg1 and nuclear actin have been shown to form a complex that is involved in the relocation of the MHC locus relative to its $\mathrm{CT}$ in response to INF $\gamma$ (Christova et al., 2007). We hypothesized that Brgl could be involved in mediating the relocation of the EDC towards the nuclear interior and in establishing the $3 \mathrm{D}$ organisation of the genome and lineage-specific programme of differentiation in epidermal progenitor cells.

qRT-PCR and immunofluorescence analysis showed that Brg1 mRNA and protein levels are significantly decreased in the epidermis of E16.5 $p 63^{-/-}$mice in comparison to WT mice (Fig. 4A,B). Furthermore, a chromatin immunoprecipitation (ChIP) assay and subsequent qPCR showed, in mouse epidermal keratinocytes, a significant enrichment of anti-p63 antibody binding to the intron 1 region of $\mathrm{Brg} 1$, a region that contains the consensus DNA-binding site of transcription factor p63 (Fig. 4C,D). In short, these data identified $\mathrm{Brg} 1$ as a direct transcriptional target of $\mathrm{p} 63$.

To gain mechanistic insights into the role of $\mathrm{Brg} 1$ in the regulation of EDC positioning within the nucleus and of gene expression within this region, $K 14-C r e E R T 2 / B r g l^{f l f l}$ mice [hereafter Brgl(i)ep] were used as a model (Indra et al., 2005). The epidermis of E16.5 $\mathrm{Brgl}(\mathrm{i}) \mathrm{ep}^{-1-}$ foetuses showed a marked decrease in Brgl protein and transcript levels (Fig. 5A,C). E16.5 $\mathrm{Brgl}\left(\mathrm{i}_{\text { ep }}{ }^{-/}\right.$mice showed a reduction in epidermal thickness compared with WT controls (supplementary material Fig. S2A,B). However, levels of proliferation and apoptosis among basal epidermal cells in E16.5 Brgl(i)ep ${ }^{-/}$and WT mice were not significantly different (supplementary material Fig. S2C; data not shown), a finding consistent with previously published data (Indra et al., 2005).

Microarray, qRT-PCR and immunohistochemical analyses of E16.5 $\mathrm{Brgl}(\mathrm{i}) \mathrm{ep}^{-/}$laser-captured epidermis showed a marked downregulation of genes that comprise the central EDC domain, including Lor and several members of the Lce family, compared with age-matched WT epidermis (Fig. 5B-D; supplementary material Table S4). In addition, sequencing of DNA isolated from formaldehyde cross-linked chromatin fragments immunoprecipitated with anti-Brg1 antibody from primary epidermal keratinocytes showed Brgl binding in the vicinity of the regulatory regions/transcription start sites of numerous genes within the EDC central domain and flanking regions (Fig. 5E).

To check whether Brgl contributes to the relocation of Lor within MMU3 during epidermal development, we analysed the position of the entire EDC locus, Lor and Rps 27 relative to either one another or to MMU3 in E16.5 $\mathrm{Brgl}^{(\mathrm{i}) \mathrm{ep}^{-/}}$and E16.5 WT basal epidermal cells. 3D-FISH analyses showed a significant increase in the proportion of EDC and Lor loci located at the periphery of MMU3, and an increase in the distance between Lor

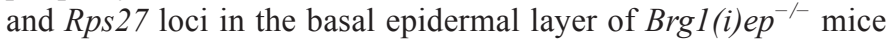
compared with WT basal keratinocytes (Fig. 5F-I). Furthermore, the number of SC35-positive nuclear speckles within the vicinity of the EDC was significantly $(P<0.05)$ reduced in the epidermis of Brgl(i) $\mathrm{ep}^{-/}$mice compared with WT mice (Fig. 5J; supplementary material Fig. S2D). 
A

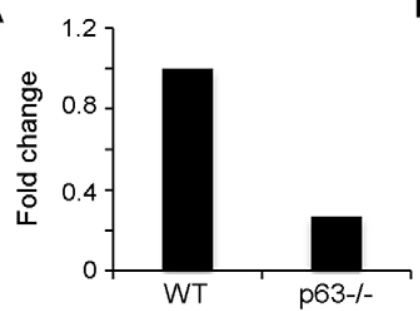

C

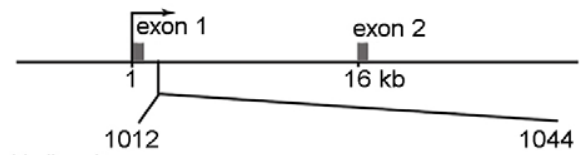

binding site: AAACAAGTTTttgtttgaactgaCAGACAGCCT consensuS RRRCWWGYYYnnnnnnnnnnnnnRRRCWWGYYY

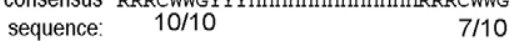

B
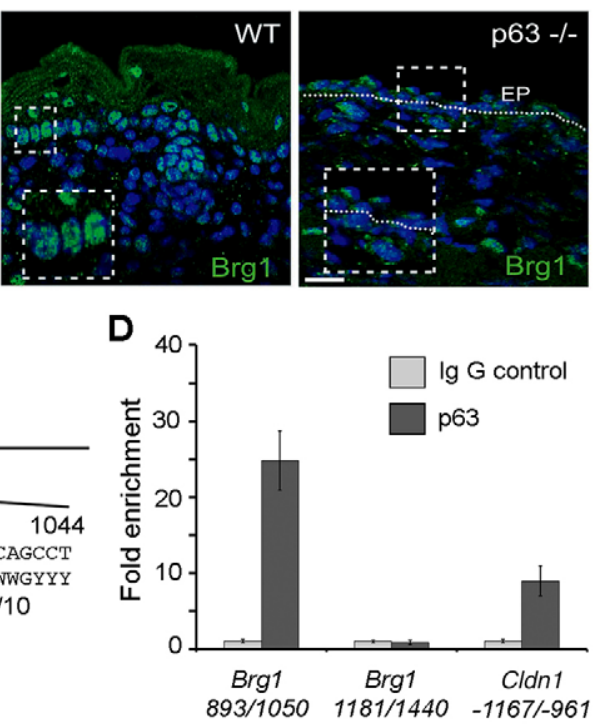

Fig. 4. Brg1 is a direct transcriptional target of p63 in epidermal keratinocytes. Expression of Brg1 mRNA (A) and protein $(B)$ is substantially reduced in the epidermis of

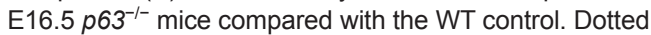
line indicates position of basement membrane (EP). Scale bar: $25 \mu \mathrm{m}$. $(C, D)$ qPCR analysis of DNA purified from cross-linked mouse primary epidermal keratinocyte chromatin after immunoprecipitation with antibodies against p63 protein or purified rabbit IgGs identified binding of p63 to the high-affinity site in the first intron of the Brg1 gene $(C, D)$ but not to the negative control site. The promoter region of Cldn1 was used as a positive control (D). Error bars indicate s.d.
These data are consistent with results obtained from the analysis of E12.5 WT embryos treated for 2 days ex vivo with Brgl or control siRNA; an increase in the incidence of Lor loci located at the periphery of MMU3 was observed after treatment with Brg1 siRNA compared with control siRNA-treated epidermis (supplementary material Fig. S3). Likewise, the intrachromosomal localisation of Rps 27 was not notably affected by treatment with Brg1 siRNA and predominantly occupied the internal part of MMU3 in both Brgl(i) ep ${ }^{-/}$and WT mice (supplementary material Fig. S3). Taken together, these data suggest that Brgl serves as a direct transcriptional target of p63 that contributes to the developmentally regulated relocation of the EDC and Lor towards the nuclear interior in epidermal progenitor cells.

\section{DISCUSSION}

Here we show that, during epidermal morphogenesis and differentiation of multipotent progenitor cells residing in the basal epidermal layer, the lineage-specific EDC locus shows marked remodelling of its higher-order chromatin structure and relocates away from the nuclear periphery into the nuclear interior. This shift in the radial position of the EDC is associated with an increase in the transcriptional activity of genes involved in the control of terminal keratinocyte differentiation and epidermal barrier formation. We demonstrate that developmentally regulated relocation of the EDC towards the nuclear interior is a keratinocytespecific event that does not involve the neighbouring Rps27 and Gabpb2 genes, does not occur in dermal cells, and is regulated, at least in part, by the lineage-specific transcription factor p63 and its direct target the ATP-dependent chromatin remodeller Brg1.

Our data are generally consistent with previous observations showing the looping out from CT1 of the EDC locus in cultured human keratinocytes, which suggests that the positioning of this genomic domain within the nucleus is flexible (Williams et al., 2002). Here, we provide the first compelling evidence that positioning of the EDC locus within the nucleus of epidermal progenitor cells is developmentally regulated in situ, and that, once established, it is maintained during adulthood despite the many cycles of cell division that occur in this rapidly proliferating and self-renewing epithelial tissue (Blanpain and Fuchs, 2009). Importantly, keratinocyte-specific positioning of the EDC within the nuclear interior is established prior to full activation of the EDC, making it likely that such changes occur not as a consequence of transcriptional activation but rather as a prerequisite for the efficient maintenance of high expression levels among genes encoded within the EDC that are associated with terminal keratinocyte differentiation.

Our data suggest that, together with the regulation of specific patterns of histone methylation and acetylation at EDC gene promoters (Ezhkova et al., 2009; Frye et al., 2007), the distinct 3D organisation and nuclear positioning of the EDC locus represent an important mechanism in the hierarchy of events underlying a programme of concerted gene expression within this locus during lineage-specific differentiation. This is also evident from the fact that neither Rps27 nor Gabpb2, which both neighbour the EDC, shows a substantial developmentally regulated change in nuclear position in either epidermal progenitor or dermal cells. Thus, higherorder chromatin remodelling within this $5 \mathrm{Mb}$ gene-rich domain on mouse chromosome 3 is apparently regulated by mechanisms operating at the level of the individual gene or gene locus.

The location of the EDC locus at the nuclear periphery in epidermal keratinocytes at E11.5 and in dermal fibroblasts during all stages of development suggests that the EDC could interact with the nuclear lamina via lamina-associated domains (LADs) (Guelen et al., 2008; Peric-Hupkes et al., 2010). Recent data show that selected regions of the EDC are incorporated into LADs in murine ES cells, and in murine embryonic fibroblasts the whole locus lies within the LAD (Peric-Hupkes et al., 2010). Our data suggest that movement of the EDC towards the nuclear interior during epidermal development might be due to the release of the genes within the locus from a repressive environment associated with the nuclear lamina. Mechanisms regulating this process need to be investigated further.

Because many actively transcribed genes demonstrate a more flexible chromatin structure in comparison with inactive genes, active genes may loop outside of the CTs or concentrate within their outermost parts (Morey et al., 2009). Our data show that relocation of the EDC locus into the nuclear interior is associated with an increase in the number of SC35-positive nuclear speckles present within the vicinity of the EDC, suggesting that this nuclear compartment might provide a 'permissive environment' for the 
A

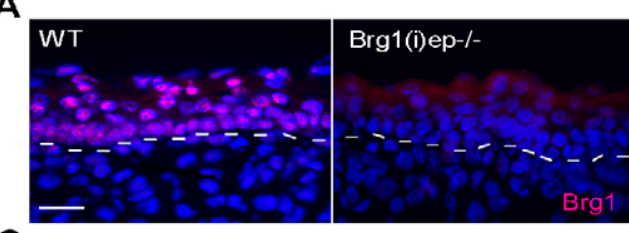

C

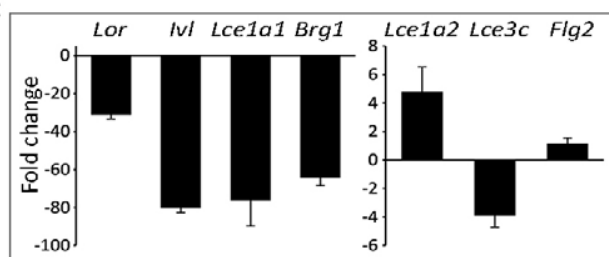

D

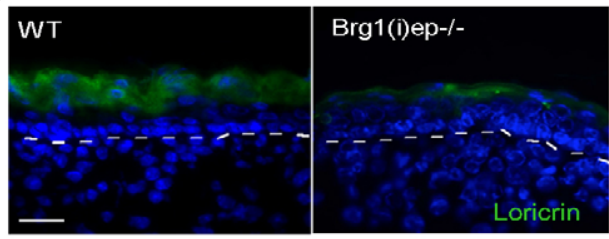

$\mathbf{F}$
B

B_ Gene name

\begin{tabular}{lccc}
\hline \multicolumn{4}{c}{ Down-regulated (Control vs Brg1(i)ep-/-) } \\
\hline Loricrin & Lor & NM_008508 & $61.63^{*}$ \\
\hline Late cornified envelope 1A1 & Lce1a1 & NM_025984 & $32.89^{*}$ \\
\hline Small proline-rich protein 2A2 & Sprr2a2 & NM_001164787 & 23.57 \\
\hline Late cornified envelope 1I & Lce1i & NM_029667 & 19.42 \\
\hline Late cornified envelope 1D & Lce1d & NM_027137 & 10.44 \\
Late cornified envelope 3F & Lce3f & NM_001018079 & 4.9 \\
\hline Late cornified envelope 1G & Lce1g & NM_025413 & 4.06 \\
Late cornified envelope 3C & Lce3c & NM_033175 & $2.79^{*}$ \\
Late cornified envelope 1H & Lce1h & NM_026335 & 2.72 \\
Small proline-rich protein 1A & Sprr1a & NM_009264 & 2.24 \\
Involucrin & Ivl & NM_008412 & $1.84^{*}$ \\
\hline Filaggrin 2 & Flg2 & NM_001013804 & $1.6^{*}$
\end{tabular}

Up-regulated (Brg1(i)ep-/- vs Control)

Late cornified envelope 1A2 $\quad$ Lce1a2 $\quad$ NM_028625 $36.92 *$

E

$\begin{array}{llll}\text { Small proline-rich protein 2D } & \text { Sprr2d } & \text { NM } 011470 & 7.73\end{array}$

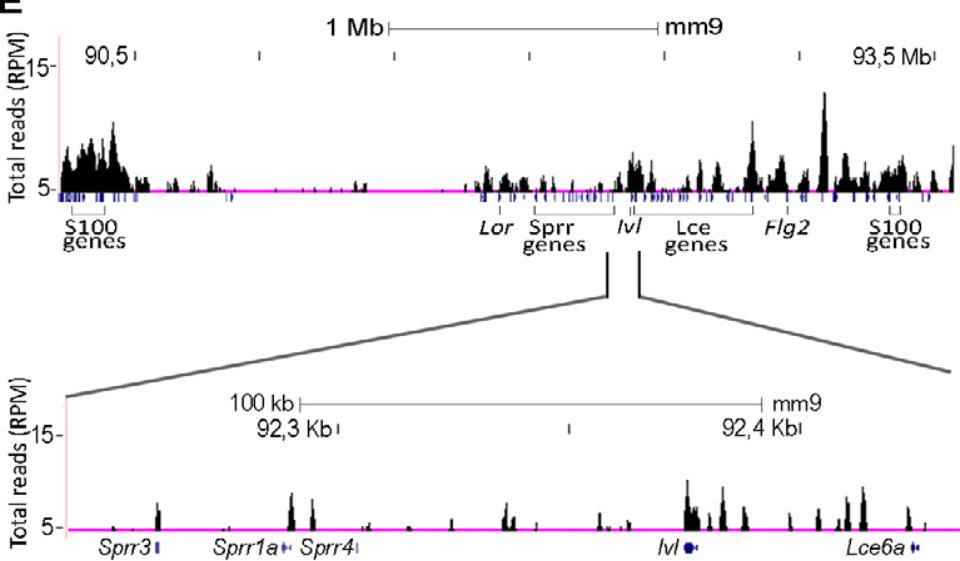

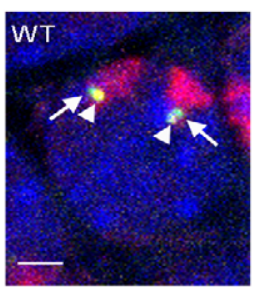

G

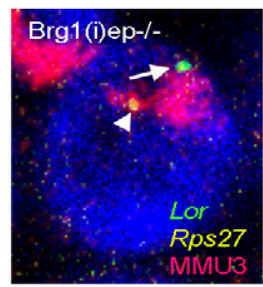

H

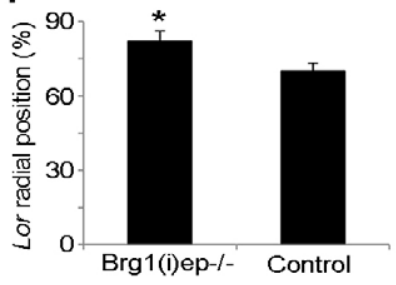

K

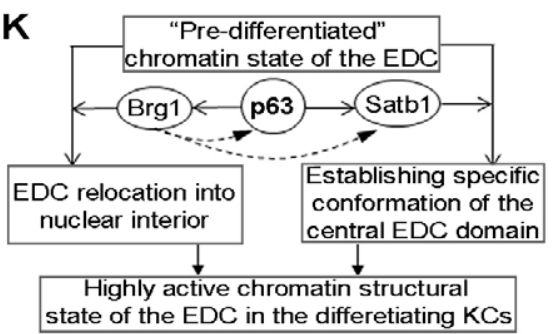

Fig. 5. Brg1 is involved in the control of gene expression and EDC intranuclear localisation in the epidermis. (A) Lack of Brg1 protein expression in the epidermis of $\mathrm{Brg} 1$ (i)e $\mathrm{p}^{-1-}$ mice at E16.5 in comparison to the control. Dashed line indicates position of basement membrane. (B) Microarray data demonstrating differences in gene expression in the EDC in the epidermis of E16.5 Brg1(i)ep ${ }^{-/-}$versus control mice. Asterisks indicate that the fold change in gene expression levels was validated by qRT-PCR. (C) qRT-PCR analysis of gene expression in the EDC in the epidermis of E16.5 Brg1(i)ep ${ }^{-/-}$mice normalised to the expression level in the control mice. (D) The reduction in Lor expression in the epidermis of E16.5 Brg1(i)ep ${ }^{-/-}$versus control mice. (E) Brg1 ChIP-Seq profiles in the EDC in mouse epidermal keratinocytes. (F) Multicolour 3D-FISH with BACs containing Lor (arrows), Rps27 (arrowheads) and MMU3 in the epidermis of Brg1(i)ep ${ }^{-/}$and control mice at E16.5. (G) Frequencies of intra-MMU3 distribution (peripheral versus internal parts of the MMU3) of EDC, Lor and Rps27 in basal epidermal cells of $B r g 1(i) e p^{-/-}$compared with control mice at E16.5. For each sample, $n=100$. $P$-values calculated for pairwise comparison (Chi-square test) are: $L o r, P=5.97 \times 10^{-6}$; EDC, $P=1.34 \times 10^{-8}$; Rps27, $P=0.09$. (H) Relative radial position of $L o r$ normalised to the average radius of the nuclei in basal epidermal keratinocytes of WT and $p 63^{-1-}$ mice at E16.5. Mean + s.e.m.; ${ }^{*} P<0.05$ (two-tailed Student's $t$-test). (I) Distances between Lor and Rps27 in basal epidermal keratinocytes in $B r g 1(i) e p^{-/-}$and control mice at E16.5. Mean + s.e.m.; $n=66$; ${ }^{*} P<0.01$ (two-tailed Student's $t$-test). (J) The number of speckles in proximity to the EDC in Brg1(i)e $p^{-/-}$mice was decreased compared with WT mice. Mean + s.e.m.; $n=80$; ${ }^{*} P<0.01$ (Dunn's test/Kruskal-Wallis test). (K) Model describing p63-mediated higher-order chromatin remodelling within the EDC locus during epidermal development (see text for further details). KCs, keratinocytes. Scale bars: $25 \mu \mathrm{m}$ in A; $2 \mu \mathrm{m}$ in F; $2 \mu \mathrm{m}$ in D. 
efficient transcription and maintenance of high expression levels among genes activated during keratinocyte differentiation. SC35positive speckles enriched in RNA metabolic factors facilitate efficient gene expression and are considered to be sites of association between active genes within the nucleus (Brown et al., 2008; Mao et al., 2011; Spector and Lamond, 2011; Yang et al., 2011). The impact that distinct speckle components have on the control of gene expression within the EDC in epidermal progenitor cells remains to be determined. Present within active chromatin domains identified within interphase nuclei using the pan-genomic Hi-C approach (Lieberman-Aiden et al., 2009), the influence that distinct sets of transcriptional and chromatin regulators and/or lineage-specific promoter-enhancer interactions exert on gene expression within the EDC also remains to elucidated (LiebermanAiden et al., 2009).

In accordance with the prior designation of the transcription factor p63 as a master regulator of epidermal development (Koster et al., 2007a; Truong and Khavari, 2007), our data demonstrate that developmentally regulated relocation of the EDC locus towards the nuclear interior in epidermal progenitor cells is regulated by p63. Recent ChIP-Seq data demonstrate that p63 binds to, and directly regulates, the expression of many of the genes that comprise the EDC (McDade et al., 2012). Demonstrable at both E14.5 and E16.5 in p63 knockout mice, ablation of p63 results in failure to activate a large cohort of genes involved in epidermal stratification during epidermal development (Fessing et al., 2011; Shalom-Feuerstein et al., 2011).

As we have shown previously, in addition to directly controlling gene expression, p63 controls the genome organiser Satb1 in epidermal progenitor cells, which, in turn, regulates the conformation of the central domain of the EDC and the genes within this region that are activated during terminal keratinocyte differentiation (Fessing et al., 2011). We show here that, in addition to Satb1, p63 also directly regulates the expression of the ATPdependent chromatin remodeller Brg1, which contributes to the developmentally regulated relocation of the EDC locus towards the nuclear interior. In turn, Brg1 binds to many regions within the EDC locus in keratinocytes and the genetic ablation of Brgl in the epidermis results in marked alterations in the expression pattern of terminal differentiation-associated genes.

It was shown previously that the ATP-dependent chromatin remodellers Brg1 and $\mathrm{Mi}-2 \beta$ are involved in the control of keratinocyte differentiation and epidermal barrier formation. Ablation of the genes encoding Brg1 and Mi-2 $\beta$ results in altered epidermal development and barrier function in mice (Indra et al., 2005; Kashiwagi et al., 2007). Both Brg1 and Mi-2 $\beta$ are essential co-regulators of transcription and they might also control local remodelling of the chromatin fibre within the EDC at the nucleosome level in an ATP-dependent manner (Cai et al., 2006; Kwon and Wagner, 2007). Brg1 binds to the promoters and distal regulatory elements of many active genes (De et al., 2011; Euskirchen et al., 2011) and is also implicated in the relocation of the human MHC locus relative to its CT in response to INF $\gamma$ treatment (Christova et al., 2007). Brg1 has also been shown to form a complex with nuclear actin and to promote the formation of cell type-specific chromatin loops between the beta-globin locus control region and downstream promoters (Clapier and Cairns, 2009). Most likely, Brg1 contributes to the formation of topologically flexible chromatin structure within the EDC locus in keratinocytes during its developmentally regulated relocation to the nuclear interior, as shown previously for other cell types (Christova et al., 2007; Clapier and Cairns, 2009). However, the mechanisms underlying the targeting of Brg1 to distinct regions of the EDC and its potential interaction with the assorted transcription factors (including p63, AP-1, Klf4) known to regulate EDC gene expression in epidermal progenitor cells remain to be further clarified.

In conjunction with data published previously (Fessing et al., 2011), we conclude that, in epidermal progenitor cells during skin development, a p63-regulated programme of chromatin remodelling within the EDC locus includes at least two interconnected steps: (1) the Brg1-dependent relocation of the EDC away from the nuclear periphery into the nuclear interior and proximity with speckles; (2) the final, Satb1-mediated arrangement of the chromatin conformation within the central domain of the locus, which contains a large number of genes activated during terminal keratinocyte differentiation (Fig. 5K). An involvement of Satb1 in the control of the developmentally regulated relocation of the EDC towards the nuclear interior seems rather unlikely (Fessing et al., 2011), but the participation of $\mathrm{Brg} 1$ and its potential cooperation with Satb1 in the establishment of a specific EDC conformation in differentiating epidermal keratinocytes needs to be investigated further. Additional analysis using 3C-based technologies will help elucidate the principles of organisation within the genomic neighbourhood of the EDC locus in epidermal progenitor cells and help to identify the mechanisms that control chromatin folding within this locus during its activation in terminally differentiated keratinocytes.

\section{MATERIALS AND METHODS}

\section{Experimental animals and tissue collection}

Animal studies were performed in accordance with protocols approved by Boston University (USA) and the UK Home Office Project License. C57Bl/6 mice were purchased from Charles River Laboratories. p63 null and WT embryos were obtained by breeding $p 63^{+/-}$animals from Jackson Laboratories. Brgl(i)ep ${ }^{-/}$foetuses were obtained by breeding K14CreERT2/Brg1L2/L2 mice with Brg1L2/L2 mice and administering tamoxifen to pregnant females from E10.5 onwards, as described previously (Indra et al., 2005). Tissue samples were processed for immunofluorescent or microarray analysis as described (Botchkarev et al., 1999a; Botchkarev et al., 1999b; Fessing et al., 2006; Sharov et al., 2006; Siebenhaar et al., 2007). For FISH and immunofluorescence analysis of 3D preserved nuclei, skin samples were prepared as described (Fessing et al., 2011; Solovei et al., 2009).

\section{LCM, microarray, qRT-PCR and immunohistochemistry}

LCM of the murine basal epidermal layer at selected stages of development and subsequent RNA isolation, amplification and microarray analyses were performed as previously described (Sharov et al., 2006). Microarrays were performed by Mogene (St Louis, MO, USA) using a $41 \mathrm{~K}$ Whole Mouse Genome 60-mer oligo microarray (Agilent Technologies). Gene expression microarray data were normalised to corresponding reference RNA data. Two independent datasets were generated for each stage of epidermal morphogenesis. $P$-values were calculated by Student's $t$-test using the distribution of background intensity and signal intensity values (Agilent Feature Extraction software version 7.5). The microarray expression data were deposited in Gene Expression Omnibus under accession number GSE50847. The function and ontology of genes listed were identified using Entrez Gene (http://www.ncbi.nlm.nih.gov/gene) (Fessing et al., 2010). Primers for qRT-PCR analyses (supplementary material Table S6) were designed using Beacon Designer (Premier Biosoft, Palo Alto, CA, USA). qRT-PCR was performed using iQ SYBR Green Supermix and the MyiQ Single-Colour Real-Time PCR Detection System (Bio-Rad) as described previously (Fessing et al., 2011). Immunohistochemical analyses were performed with the primary antibodies listed in supplementary material Table S8, as described previously (Müller-Rover et al., 1998; Peters et al., 2002). Analysis of apoptosis was performed using the TUNEL assay (Sharov et al., 2003). 


\section{D-FISH, confocal microscopy and image analysis}

Labelled DNA probes were prepared and 3D-FISH analysis performed on $20 \mu \mathrm{m}$ tissue sections, as described previously (Fessing et al., 2011; Solovei et al., 2009). Probes were synthesized by nick translation using Bio-dUTP, FITC-dUTP or Cy3-dUTP [synthesized in house according to Muller et al. (Muller et al., 2011)] using individual or pooled BAC spanning target loci (supplementary material Table S3). Whole chromosome paints were labelled with Bio-dUTP by degenerate oligonucleotide-primed (DOP)-PCR. DNA was stained with DAPI (Sigma). Immunostaining was performed on 10-20 $\mu \mathrm{m}$ quick-frozen or 3D preserved tissue with antibodies (supplementary material Table S8) using standard protocols (Fessing et al., 2006; Sharov et al., 2005). 3D immuno-FISH experiments were conducted by immunostaining tissue sections with antibodies after probe hybridisation.

Two-dimensional and 3D images were collected using a Zeiss LSM510 confocal microscope. Nuclei were scanned with a $z$-axial distance of 200 $\mathrm{nm}$, yielding separate stacks of 8-bit greyscale images, with pixel size 100$200 \mathrm{~nm}$, for each fluorescent channel. For each optical section, images were collected sequentially for all fluorophores and the axial chromatic shift corrected for in each channel (Ronneberger et al., 2008). Images were processed and analysed using Image $(\mathrm{NIH})$. The radial position of loci relative to the nuclear centre was calculated after correction for chromatic aberration by normalising locus distance from the nuclear centre to average nuclear radius, as previously described (Fessing et al., 2011). The intrachromosomal positions of loci were analysed as follows: a locus was recorded as being situated in either an internal or peripheral part of the CT according to whether the signal centre was closer to the nuclear interior or to the nuclear membrane relative to the $\mathrm{CT}$ centre. SC35-positive nuclear speckles were considered to be within the vicinity of gene loci when the corresponding fluorescent signals were found to at least partially overlap.

\section{ChIP assay}

ChIP was performed using epidermal keratinocytes isolated from newborn mouse skin and anti-p63 or anti-Brg1 antibodies (supplementary material Table S5), as previously described (Fessing et al., 2011). After ChIP, PCR analysis of Brg1 enrichment in precipitated DNA within the Cldn1 promoter (used as a positive control) (Lopardo et al., 2008) and the Brgl intronic region (used as a negative control) was performed using the primers listed in supplementary material Table S7. Indexed ChIP-Seq libraries were generated using NEBNext reagents (New England BioLabs) and ChIP libraries were sequenced on the HiSeq 2500 platform (Illumina), producing 30-70 million reads per library. Sequencing reads were aligned to the $\mathrm{mm} 9$ mouse genome assembly (Langmead et al., 2009). Specific areas of Brg1 binding were identified with Sicer (Zang et al., 2009) using default settings. The ChIP-Seq results have been deposited in Gene Expression Omnibus with accession number GSE50921.

\section{Embryonic tissue culture and inhibition of Brg1 expression using SiRNA}

Whole embryo cultures from E12.5 WT embryos were prepared and maintained as previously described (Andl et al., 2002; Botchkarev et al., 1999). Within 2 hours of culture preparation, tissue samples were transfected with Brgl siRNA or negative control scrambled siRNA (Dhermacon/Thermo Fisher Scientific) at a final concentration of $100 \mathrm{nM}$ using RNAiMax reagent (Invitrogen) as described (Fessing et al., 2011). Forty-eight hours post-transfection, tissue was prepared to preserve the spatial structure of nuclei for 3D-FISH analysis (see above). siRNA penetration into the tissue under the experimental conditions employed was demonstrated using Block-IT fluorescent oligo (Invitrogen) in parallel experiments.

\section{Statistical analysis}

Intrachromosomal locus position frequencies were analysed by Chi-square test (significance level, $\alpha=0.05$ ). Where more than two samples were compared, Bonferroni adjustment was applied to avoid inflated type I error rates. Histogram plots of radial position and intergene distance data were generated to evaluate the normality of the distribution of these datasets. Equality of variances was assessed using Levene's test. For pairwise comparisons, a two-tailed $t$-test $(\alpha=0.05)$ was employed. Where multiple samples were compared, one-way analysis of variances (ANOVA) was used, followed by the Newman-Keuls test $(\alpha=0.05)$. Statistical comparison between SC35-positive speckle count datasets was made using the MannWhitney U-test.

\section{Acknowledgements}

We greatly appreciate the invaluable help and support of Prof. T. Cremer, Dr I. Solovei and Dr B. Joffe (Ludwig-Maximilians University Munich, Germany) in establishing 3D-FISH technology and analysis.

\section{Competing interests}

The authors declare no competing financial interests.

\section{Author contributions}

A.N.M. designed and undertook experiments, analysed results and helped write the paper; M.R.G. and J.L.Y. undertook experiments, analysed results and helped to write the paper; V.N.E., A.A.S., T.Y.S. and J.A.S. undertook experiments and analysed results; K.P. analysed results and helped to write the paper; P.C. provided crucial reagents and helped to write the paper; V.A.B. and M.Y.F. designed the experiments, analysed results and wrote the paper.

\section{Funding}

This study was supported in part by grants from the Medical Research Council UK [G0901666/1, MR/K008870/1] and the National Institutes of Health USA

[AR049778] to V.A.B. Deposited in PMC for release after 6 months.

\section{Supplementary material}

Supplementary material available online at

http://dev.biologists.org/lookup/suppl/doi:10.1242/dev.103200//DC1

\section{References}

Aarenstrup, L., Flindt, E. N., Otkjaer, K., Kirkegaard, M., Andersen, J. S. and Kristiansen, K. (2008). HDAC activity is required for p65/RelA-dependent repression of PPARdelta-mediated transactivation in human keratinocytes. J. Invest. Dermatol. 128, 1095-1106.

Andl, T., Reddy, S. T., Gaddapara, T. and Millar, S. E. (2002). WNT signals are required for the initiation of hair follicle development. Dev. Cell 2, 643-653.

Bickmore, W. A. and van Steensel, B. (2013). Genome architecture: domain organization of interphase chromosomes. Cell 152, 1270-1284.

Blanpain, C. and Fuchs, E. (2009). Epidermal homeostasis: a balancing act of stem cells in the skin. Nat. Rev. Mol. Cell Biol. 10, 207-217.

Botchkarev, V. A., Botchkareva, N. V., Roth, W., Nakamura, M., Chen, L.-H., Herzog, W., Lindner, G., McMahon, J. A., Peters, C., Lauster, R. et al. (1999a). Noggin is a mesenchymally derived stimulator of hair-follicle induction. Nat. Cell Biol. 1, 158-164.

Botchkarev, V. A., Peters, E. M. J., Botchkareva, N. V., Maurer, M. and Paus, R. (1999b). Hair cycle-dependent changes in adrenergic skin innervation, and hair growth modulation by adrenergic drugs. J. Invest. Dermatol. 113, 878-887.

Botchkarev, V. A., Gdula, M. R., Mardaryev, A. N., Sharov, A. A. and Fessing, M. Y. (2012). Epigenetic regulation of gene expression in keratinocytes. J. Invest. Dermatol. 132, 2505-2521.

Boyle, S., Rodesch, M. J., Halvensleben, H. A., Jeddeloh, J. A. and Bickmore, W. A. (2011). Fluorescence in situ hybridization with high-complexity repeat-free oligonucleotide probes generated by massively parallel synthesis. Chromosome Res. 19, 901-909.

Brown, J. M., Green, J., das Neves, R. P., Wallace, H. A., Smith, A. J., Hughes, J., Gray, N., Taylor, S., Wood, W. G., Higgs, D. R. et al. (2008). Association between active genes occurs at nuclear speckles and is modulated by chromatin environment. J. Cell Biol. 182, 1083-1097.

Cai, S., Lee, C. C. and Kohwi-Shigematsu, T. (2006). SATB1 packages densely looped, transcriptionally active chromatin for coordinated expression of cytokine genes. Nat. Genet. 38, 1278-1288.

Chambeyron, S. and Bickmore, W. A. (2004). Chromatin decondensation and nuclear reorganization of the HoxB locus upon induction of transcription. Genes Dev. $18,1119-1130$

Chambeyron, S., Da Silva, N. R., Lawson, K. A. and Bickmore, W. A. (2005). Nuclear re-organisation of the Hoxb complex during mouse embryonic development. Development 132, 2215-2223

Christova, R., Jones, T., Wu, P. J., Bolzer, A., Costa-Pereira, A. P., Watling, D., Kerr, I. M. and Sheer, D. (2007). P-STAT1 mediates higher-order chromatin remodelling of the human MHC in response to IFNgamma. J. Cell Sci. 120, 32623270 .

Clapier, C. R. and Cairns, B. R. (2009). The biology of chromatin remodeling complexes. Annu. Rev. Biochem. 78, 273-304.

Cremer, T. and Cremer, M. (2010). Chromosome territories. Cold Spring Harb. Perspect. Biol. 2, a003889.

De, S., Wurster, A. L., Precht, P., Wood, W. H., III, Becker, K. G. and Pazin, M. J. (2011). Dynamic BRG1 recruitment during $T$ helper differentiation and activation reveals distal regulatory elements. Mol. Cell. Biol. 31, 1512-1527. 
de Guzman Strong, C., Conlan, S., Deming, C. B., Cheng, J., Sears, K. E. and Segre, J. A. (2010). A milieu of regulatory elements in the epidermal differentiation complex syntenic block: implications for atopic dermatitis and psoriasis. Hum. Mol. Genet. 19, 1453-1460.

Driskell, I., Oda, H., Blanco, S., Nascimento, E., Humphreys, P. and Frye, M. (2012). The histone methyltransferase Setd8 acts in concert with c-Myc and is required to maintain skin. EMBO J. 31, 616-629.

Eckert, R. L., Adhikary, G., Rorke, E. A., Chew, Y. C. and Balasubramanian, S. (2011). Polycomb group proteins are key regulators of keratinocyte function. $J$. Invest. Dermatol. 131, 295-301.

Euskirchen, G. M., Auerbach, R. K., Davidov, E., Gianoulis, T. A., Zhong, G., Rozowsky, J., Bhardwaj, N., Gerstein, M. B. and Snyder, M. (2011). Diverse roles and interactions of the SWI/SNF chromatin remodeling complex revealed using global approaches. PLoS Genet. 7, e1002008

Ezhkova, E., Pasolli, H. A., Parker, J. S., Stokes, N., Su, I. H., Hannon, G., Tarakhovsky, A. and Fuchs, E. (2009). Ezh2 orchestrates gene expression for the stepwise differentiation of tissue-specific stem cells. Cell 136, 1122-1135.

Ezhkova, E., Lien, W. H., Stokes, N., Pasolli, H. A., Silva, J. M. and Fuchs, E. (2011). EZH1 and EZH2 cogovern histone H3K27 trimethylation and are essential for hair follicle homeostasis and wound repair. Genes Dev. 25, 485-498.

Ferrai, C., Xie, S. Q., Luraghi, P., Munari, D., Ramirez, F., Branco, M. R., Pombo, A. and Crippa, M. P. (2010). Poised transcription factories prime silent uPA gene prior to activation. PLoS Biol. 8, e1000270.

Fessing, M. Y., Sharova, T. Y., Sharov, A. A., Atoyan, R. and Botchkarev, V. A (2006). Involvement of the Edar signaling in the control of hair follicle involution (catagen). Am. J. Pathol. 169, 2075-2084.

Fessing, M. Y., Atoyan, R., Shander, B., Mardaryev, A. N., Botchkarev, V. V., Jr, Poterlowicz, K., Peng, Y., Efimova, T. and Botchkarev, V. A. (2010). BMP signaling induces cell-type-specific changes in gene expression programs of human keratinocytes and fibroblasts. J. Invest. Dermatol. 130, 398-404.

Fessing, M. Y., Mardaryev, A. N., Gdula, M. R., Sharov, A. A., Sharova, T. Y. Rapisarda, V., Gordon, K. B., Smorodchenko, A. D., Poterlowicz, K., Ferone, G. et al. (2011). p63 regulates Satb1 to control tissue-specific chromatin remodeling during development of the epidermis. J. Cell Biol. 194, 825-839.

Frye, M. and Benitah, S. A. (2012). Chromatin regulators in mammalian epidermis. Semin. Cell Dev. Biol. 23, 897-905.

Frye, M., Fisher, A. G. and Watt, F. M. (2007). Epidermal stem cells are defined by global histone modifications that are altered by Myc-induced differentiation. PLOS ONE 2, e763.

Gierman, H. J., Indemans, M. H., Koster, J., Goetze, S., Seppen, J., Geerts, D., van Driel, R. and Versteeg, R. (2007). Domain-wide regulation of gene expression in the human genome. Genome Res. 17, 1286-1295.

Goetze, S., Mateos-Langerak, J., Gierman, H. J., de Leeuw, W., Giromus, O., Indemans, M. H., Koster, J., Ondrej, V., Versteeg, R. and van Driel, R. (2007). The three-dimensional structure of human interphase chromosomes is related to the transcriptome map. Mol. Cell. Biol. 27, 4475-4487.

Guelen, L., Pagie, L., Brasset, E., Meuleman, W., Faza, M. B., Talhout, W., Eussen, B. H., de Klein, A., Wessels, L., de Laat, W. et al. (2008). Domain organization of human chromosomes revealed by mapping of nuclear lamina interactions. Nature 453, 948-951.

Hubner, M. R., Eckersley-Maslin, M. A. and Spector, D. L. (2013). Chromatin organization and transcriptional regulation. Curr. Opin. Genet. Dev. 23, 89-95.

Indra, A. K., Dupé, V., Bornert, J. M., Messaddeq, N., Yaniv, M., Mark, M., Chambon, P. and Metzger, D. (2005). Temporally controlled targeted somatic mutagenesis in embryonic surface ectoderm and fetal epidermal keratinocytes unveils two distinct developmental functions of BRG1 in limb morphogenesis and skin barrier formation. Development 132, 4533-4544.

Kashiwagi, M., Morgan, B. A. and Georgopoulos, K. (2007). The chromatin remodeler Mi-2beta is required for establishment of the basal epidermis and normal differentiation of its progeny. Development 134, 1571-1582.

Kosak, S. T., Skok, J. A., Medina, K. L., Riblet, R., Le Beau, M. M., Fisher, A. G. and Singh, H. (2002). Subnuclear compartmentalization of immunoglobulin loci during lymphocyte development. Science 296, 158-162.

Koster, M. I., Kim, S., Mills, A. A., DeMayo, F. J. and Roop, D. R. (2004). p63 is the molecular switch for initiation of an epithelial stratification program. Genes Dev. 18, 126-131

Koster, M. I., Dai, D., Marinari, B., Sano, Y., Costanzo, A., Karin, M. and Roop, D. R. (2007a). p63 induces key target genes required for epidermal morphogenesis. Proc. Natl. Acad. Sci. USA 104, 3255-3260.

Koster, M. I., Dai, D. and Roop, D. R. (2007b). Conflicting roles for p63 in skin development and carcinogenesis. Cell Cycle 6, 269-273.

Küpper, K., Kölbl, A., Biener, D., Dittrich, S., von Hase, J., Thormeyer, T., Fiegler, H., Carter, N. P., Speicher, M. R., Cremer, T. et al. (2007). Radial chromatin positioning is shaped by local gene density, not by gene expression. Chromosoma 116, 285-306.

Kwon, C. S. and Wagner, D. (2007). Unwinding chromatin for development and growth: a few genes at a time. Trends Genet. 23, 403-412.

Langmead, B., Trapnell, C., Pop, M. and Salzberg, S. L. (2009). Ultrafast and memory-efficient alignment of short DNA sequences to the human genome. Genome Biol. 10, R25.

Lieberman-Aiden, E., van Berkum, N. L., Williams, L., Imakaev, M., Ragoczy, T., Telling, A., Amit, I., Lajoie, B. R., Sabo, P. J., Dorschner, M. O. et al. (2009). Comprehensive mapping of long-range interactions reveals folding principles of the human genome. Science 326, 289-293.
Lien, W. H., Guo, X., Polak, L., Lawton, L. N., Young, R. A., Zheng, D. and Fuchs, E. (2011). Genome-wide maps of histone modifications unwind in vivo chromatin states of the hair follicle lineage. Cell Stem Cell 9, 219-232.

Lopardo, T., Lo lacono, N., Marinari, B., Giustizieri, M. L., Cyr, D. G., Merlo, G., Crosti, F., Costanzo, A. and Guerrini, L. (2008). Claudin-1 is a p63 target gene with a crucial role in epithelial development. PLOS ONE 3, e2715.

Luis, N. M., Morey, L., Mejetta, S., Pascual, G., Janich, P., Kuebler, B., Cozutto, L., Roma, G., Nascimento, E., Frye, M. et al. (2011). Regulation of human epidermal stem cell proliferation and senescence requires polycomb- dependent and independent functions of Cbx4. Cell Stem Cell 9, 233-246.

Mao, Y. S., Zhang, B. and Spector, D. L. (2011). Biogenesis and function of nuclear bodies. Trends Genet. 27, 295-306.

Markaki, Y., Gunkel, M., Schermelleh, L., Beichmanis, S., Neumann, J., Heidemann, M., Leonhardt, H., Eick, D., Cremer, C. and Cremer, T. (2010). Functional nuclear organization of transcription and DNA replication: a topographical marriage between chromatin domains and the interchromatin compartment. Cold Spring Harb. Symp. Quant. Biol. 75, 475-492.

Martin, N., Patel, S. and Segre, J. A. (2004). Long-range comparison of human and mouse Sprr loci to identify conserved noncoding sequences involved in coordinate regulation. Genome Res. 14, 2430-2438.

McDade, S. S., Henry, A. E., Pivato, G. P., Kozarewa, I., Mitsopoulos, C., Fenwick, K., Assiotis, I., Hakas, J., Zvelebil, M., Orr, N. et al. (2012). Genome-wide analysis of p63 binding sites identifies AP-2 factors as co-regulators of epidermal differentiation. Nucleic Acids Res. 40, 7190-7206.

Mejetta, S., Morey, L., Pascual, G., Kuebler, B., Mysliwiec, M. R., Lee, Y., Shiekhattar, R., Di Croce, L. and Benitah, S. A. (2011). Jarid2 regulates mouse epidermal stem cell activation and differentiation. EMBO J. 30, 3635-3646.

Mills, A. A., Zheng, B., Wang, X. J., Vogel, H., Roop, D. R. and Bradley, A. (1999). p63 is a p53 homologue required for limb and epidermal morphogenesis. Nature 398, 708-713.

Morey, C., Kress, C. and Bickmore, W. A. (2009). Lack of bystander activation shows that localization exterior to chromosome territories is not sufficient to up-regulate gene expression. Genome Res. 19, 1184-1194.

Muller, S., Neusser M, Kohler, D. and Cremer, M. (2007). Preparation of complex DNA probe sets for 3D FISH with up to six different fluorochromes. CSH Protocols, doi: $10.1101 / p d b . p r o t 4730$

Müller-Röver, S., Peters, E. J., Botchkarev, V. A., Panteleyev, A. and Paus, R. (1998). Distinct patterns of NCAM expression are associated with defined stages of murine hair follicle morphogenesis and regression. J. Histochem. Cytochem. 46, 1401-1409.

Naumova, N. and Dekker, J. (2010). Integrating one-dimensional and threedimensional maps of genomes. J. Cell Sci. 123, 1979-1988.

Nguyen, B. C., Lefort, K., Mandinova, A., Antonini, D., Devgan, V., Della Gatta, G., Koster, M. I., Zhang, Z., Wang, J., Tommasi di Vignano, A. et al. (2006). Crossregulation between Notch and p63 in keratinocyte commitment to differentiation. Genes Dev. 20, 1028-1042.

Peric-Hupkes, D., Meuleman, W., Pagie, L., Bruggeman, S. W., Solovei, I., Brugman, W., Gräf, S., Flicek, P., Kerkhoven, R. M., van Lohuizen, M. et al. (2010). Molecular maps of the reorganization of genome-nuclear lamina interactions during differentiation. Mol. Cell 38, 603-613.

Peters, E. M., Botchkarev, V. A., Müller-Röver, S., Moll, I., Rice, F. L. and Paus, R. (2002). Developmental timing of hair follicle and dorsal skin innervation in mice. J. Comp. Neurol. 448, 28-52.

Rando, O. J. and Chang, H. Y. (2009). Genome-wide views of chromatin structure. Annu. Rev. Biochem. 78, 245-271.

Ronneberger, O., Baddeley, D., Scheipl, F., Verveer, P. J., Burkhardt, H., Cremer, C., Fahrmeir, L., Cremer, T. and Joffe, B. (2008). Spatial quantitative analysis of fluorescently labeled nuclear structures: problems, methods, pitfalls. Chromosome Res. 16, 523-562.

Segre, J. A. (2006). Epidermal barrier formation and recovery in skin disorders. J. Clin. Invest. 116, 1150-1158.

Sen, G. L., Reuter, J. A., Webster, D. E., Zhu, L. and Khavari, P. A. (2010). DNMT1 maintains progenitor function in self-renewing somatic tissue. Nature 463, 563-567.

Shalom-Feuerstein, R., Lena, A. M., Zhou, H., De La Forest Divonne, S., Van Bokhoven, H., Candi, E., Melino, G. and Aberdam, D. (2011). $\Delta$ Np63 is an ectodermal gatekeeper of epidermal morphogenesis. Cell Death Differ. 18, 887-896.

Sharov, A. A., Weiner, L., Sharova, T. Y., Siebenhaar, F., Atoyan, R., Reginato, A. M., McNamara, C. A., Funa, K., Gilchrest, B. A., Brissette, J. L. et al. (2003). Noggin overexpression inhibits eyelid opening by altering epidermal apoptosis and differentiation. EMBO J. 22, 2992-3003.

Sharov, A. A., Fessing, M., Atoyan, R., Sharova, T. Y., Haskell-Luevano, C., Weiner, L., Funa, K., Brissette, J. L., Gilchrest, B. A. and Botchkarev, V. A. (2005). Bone morphogenetic protein (BMP) signaling controls hair pigmentation by means of cross-talk with the melanocortin receptor-1 pathway. Proc. Natl. Acad. Sci. USA 102, 93-98.

Sharov, A. A., Sharova, T. Y., Mardaryev, A. N., Tommasi di Vignano, A., Atoyan, R., Weiner, L., Yang, S., Brissette, J. L., Dotto, G. P. and Botchkarev, V. A. (2006). Bone morphogenetic protein signaling regulates the size of hair follicles and modulates the expression of cell cycle-associated genes. Proc. Natl. Acad. Sci. USA 103, 18166-18171.

Schoenefelder, S., Clay, I. and Fraser, P. (2010). The transcription interactome: gene expression in 3D. Curr. Opin. Genet. Dev. 20, 127-133.

Siebenhaar, F., Sharov, A. A., Peters, E. M. J., Sharova, T. Y., Syska, W. Mardaryev, A. N., Freyschmidt-Paul, P., Sundberg, J. P., Maurer, M. and Botchkarev, V. A. (2007). Substance P as an immunomodulatory neuropeptide in a 
mouse model for autoimmune hair loss (alopecia areata). J. Invest. Dermatol. 127, 1489-1497.

Solovei, I., Kreysing, M., Lanctôt, C., Kösem, S., Peichl, L., Cremer, T., Guck, J. and Joffe, B. (2009). Nuclear architecture of rod photoreceptor cells adapts to vision in mammalian evolution. Cell 137, 356-368.

Spector, D. L. and Lamond, A. I. (2011). Nuclear speckles. Cold Spring Harb. Perspect. Biol. 3, a000646.

Takizawa, T., Gudla, P. R., Guo, L., Lockett, S. and Misteli, T. (2008). Allele-specific nuclear positioning of the monoallelically expressed astrocyte marker GFAP. Genes Dev. 22, 489-498.

Truong, A. B. and Khavari, P. A. (2007). Control of keratinocyte proliferation and differentiation by p63. Cell Cycle 6, 295-299.

Wang, Z., Schones, D. E. and Zhao, K. (2009). Characterization of human epigenomes. Curr. Opin. Genet. Dev. 19, 127-134.

Williams, R. R., Broad, S., Sheer, D. and Ragoussis, J. (2002). Subchromosomal positioning of the epidermal differentiation complex (EDC) in keratinocyte and lymphoblast interphase nuclei. Exp. Cell Res. 272, 163-175.

Williams, C. J., Naito, T., Arco, P. G., Seavitt, J. R., Cashman, S. M., De Souza, B., Qi, X., Keables, P., Von Andrian, U. H. and Georgopoulos, K. (2004). The chromatin remodeler Mi-2beta is required for CD4 expression and T cell development. Immunity 20, 719-733.
Williams, R. R., Azuara, V., Perry, P., Sauer, S., Dvorkina, M., Jørgensen, H., Roix, J., McQueen, P., Misteli, T., Merkenschlager, M. et al. (2006). Neural induction promotes large-scale chromatin reorganisation of the Mash1 locus. J. Cell Sci. 119, 132-140.

Xiong, Y., Li, W., Shang, C., Chen, R. M., Han, P., Yang, J., Stankunas, K., Wu, B., Pan, M., Zhou, B. et al. (2013). Brg1 governs a positive feedback circuit in the hair follicle for tissue regeneration and repair. Dev. Cell 25, 169-181.

Yang, A., Schweitzer, R., Sun, D., Kaghad, M., Walker, N., Bronson, R. T., Tabin, C., Sharpe, A., Caput, D., Crum, C. et al. (1999). p63 is essential for regenerative proliferation in limb, craniofacial and epithelial development. Nature 398, 714718

Yang, L., Lin, C., Liu, W., Zhang, J., Ohgi, K. A., Grinstein, J. D., Dorrestein, P. C. and Rosenfeld, M. G. (2011). ncRNA- and Pc2 methylation-dependent gene relocation between nuclear structures mediates gene activation programs. Cell 147, 773-788.

Zang, C., Schones, D. E., Zeng, C., Cui, K., Zhao, K. and Peng, W. (2009). A clustering approach for identification of enriched domains from histone modification ChIP-Seq data. Bioinformatics 25, 1952-1958.

Zhang, J., Bardot, E. and Ezhkova, E. (2012). Epigenetic regulation of skin: focus on the Polycomb complex. Cell. Mol. Life Sci. 69, 2161-2172. 